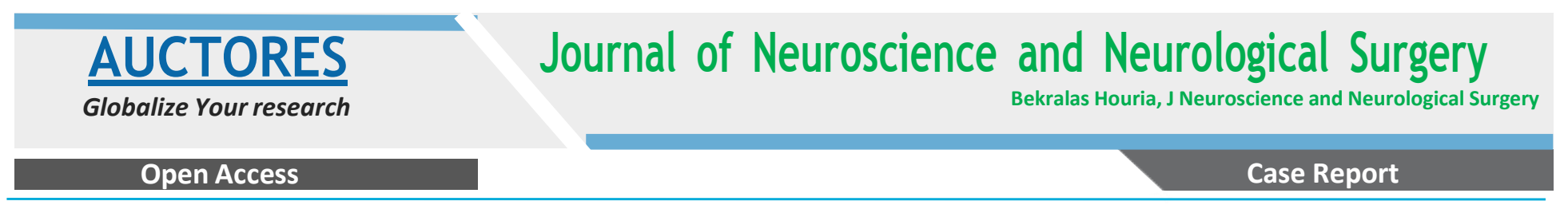

\title{
Extradural Ependymoma Mimicking A Schwannoma: Case Report and Review of the Literature.
}

Bekralas $\mathrm{H}^{{ }^{*}}$, Bouallag $\mathbf{M}^{1}$, Habchi $\mathbf{N}^{1}$, Bahria $\mathrm{E}^{1}$, Boulaouad $\mathbf{W}^{1}$, Oumchiche $\mathbf{W}^{1}$, and Djaafer $\mathbf{M}^{1}$.

${ }^{1}$ Department of Neurosurgery, Mustapha PACHA Hospital Algiers, Algeria.

* Corresponding Author: Bekralas Houria, Department of Neurosurgery,Mustapha PACHA Hospital Algiers.

Received date: February 18, 2019; Accepted date : March 03, 2019; Published date: March 08, 2019.

Citation : Bekralas H, Bouallag M , Habchi N, Bahria E, Boulaouad W, Oumchiche W, and Djaafer M ,Extradural Ependymoma Mimicking A Schwannoma: Case Report and Review of the Literature, J. Neuroscience and Neurological Surgery, 4(1); Doi:10.31579/2578-8868/048

Copyright: @ 2019 Bekralas Houria. This is an open-access article distributed under the terms of The Creative Commons Attribution License, which permits unrestricted use, distribution, and reproduction in any medium, provided the original author and source are credited.

\begin{abstract}
Intracranial ependymomas are tumors derived from ependymal cells. In addition to the problems of excision posed by their location, intracranial ependymomas have a prognosis that is difficult to define because of the risk of recurrence or neurological dessimination at a distance from the initial focus. We report a clinical case of a patient operated in 2009 of an ependymoma grade II in right temporal, reoperated in $\mathbf{2 0 1 4}$ for a grade III anaplastic ependymoma in the sacral region. This case has been studied in order to draw attention to this particular secondary localization of intracranial ependymoma.
\end{abstract}

Keywords: intracranial ependymomas, dessimination, schwanoma .

\section{Introduction}

Intracranial ependymomas account for 4-6\% of central nervous system tumors. Dissemination to the spinal canal is of the order of $10 \%(1,6$ and 8). This is related to an infra-tentorial localization, an incomplete resection and a high grade ependymoma.

\section{Case Report}

This is a patient aged 50 years, female, operated in 2009 of a grade II ependymoma located in the right temporal(figure 1), excision was subtotal followed by complementary radiotherapy.

The post-operative evolution is favorable both clinically and radiologically (figure 2).

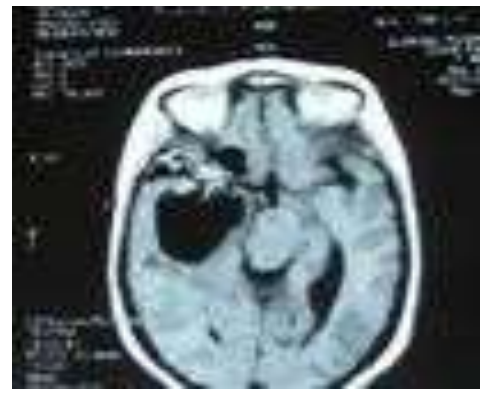

Figure 1 : T1 with gadolinium: cystic and fleshy cavity.

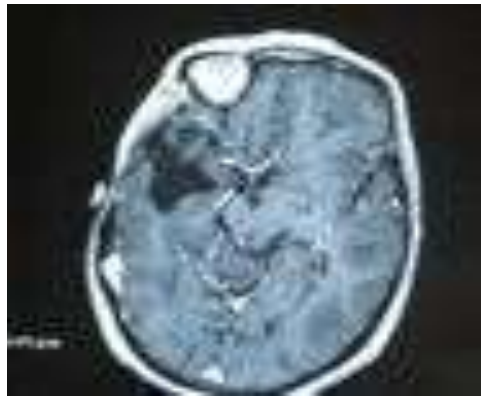

Figure 2: T1 with gadolinium: postoperative sequelae cavity double component process.
In December 2014, the patient reconsisated for lumbosacralgia of the right L5 type with monoparesis of the lower right limb and vesico sphincteric disorders. T1 MRI without and with gadolinium, T2 objective an extra dural process in hourglass eroding the posterior wall of S1 evoking an hourglass neuroma (figure 3 and 4).

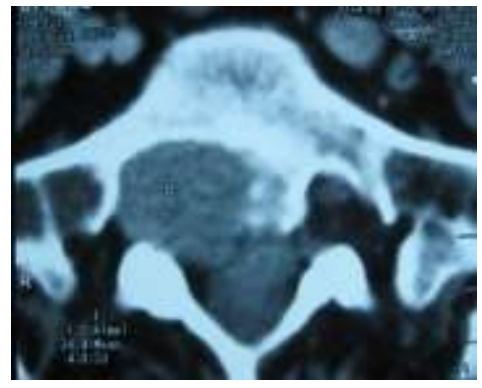

Figure 3: CT with contrast medium

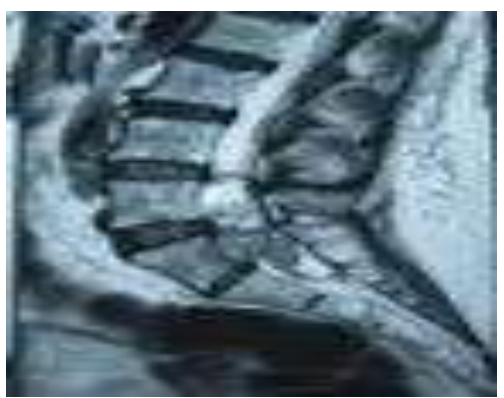

Figure 4: T2: Heterogenous.

Extradural intra-canalar tumor with regular contours and weakly contrasting "hourglass shaped".

\section{Results}

Clinical evolution is favorable, recovery on the algebraic level and motor with persistence of vesical disorders. Postoperative imaging (MRI) does not find a tumor residue (figure 5).

The patient was operated: the excision is gross macroscopic; 


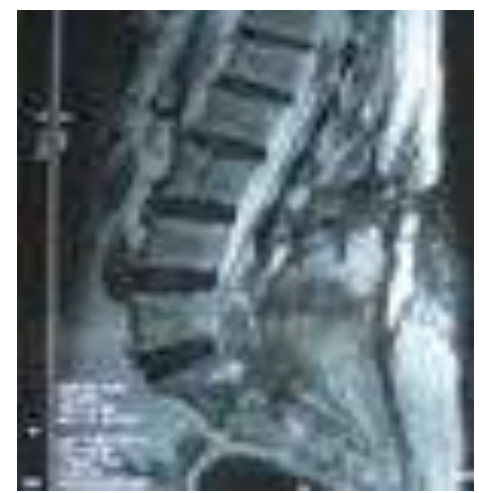

Figure 5: T2: No tumor residue.

The anatomopathological examination favors an anaplastic ependymoma grade III.

\section{Discussion}

Dissemination of low grade intra-cranial ependymomas is rare, especially if the primary tumor is well controlled. (Metellus: 1 case / 114 cases of intra-cranial ependymomas, Lyon's et al, 3 cases / 219 cases of low grade ependymomas developed spinal dissemination).

The extra dural ependymoma is exceptional (1st case reported by P De Bonis and $\mathrm{N}$ Montano in the journal of neurology, neurosurgery and psychiatry in 2009).

The most common siege of extradural ependymomas is the sacral region [3, 5]. Pathogenesis: remnants of embryonic cells during the life of a woman.

The clinical symptomatology is varied, it can go from a simple lumbalgie to lombosciatalgies associated with neurological signs, these last signs result from the compression of the nervous elements.

Bone changes(erosion of the pedicle external surface or vertebral scalloping can be seen in 63\% [2] making the differential diagnosis with neurofibroma difficult.

The radiological appearance on MRI is sometimes atypical, which may be mistaken for the diagnosis of neurofibroma. The main objective of surgery is total resection: (according to wager.M et al., Total excision is possible in $100 \%$ of neurinomas and $85 \%$ of ependymomas of the ponytail). Complementary radiotherapy is indicated in cases of incomplete resection and can be used to control recurrence (not proven in extradural ependymomas: [6].

Chemotherapy: reserved for cases refractory to surgery and radiotherapy has little proven effectiveness[8].

The prognosis is depended on the quality of the excision because of the risk of local recurrence and /or metastases. The risk of local recurrence is estimated of $60 \%$, those of metastases to neighboring organs is of the order of $20 \%$.

\section{Conclusion}

It is not always easy to differentiate an extradural ependymoma from a neurofibroma based solely on clinical and imaging. Although extradural ependymoma is a rare entity, it must be mentioned as a differential diagnosis.

\section{References}

1. Augusto Iunes, João Norberto Stávale, Rita de Cássia Caldas Pessoa, Ric ardo Ansai, and Franz Jooji Onishi, et al, (2011) Multifocal intradural extramedullary ependymomaJ Neurosurg Spine 14:65-70,

2. G. Bademci K. Tun E. Erden C. Evliyaoglu and A. Unlu, et al (2007) Late dissemination of ependymoma: case report Neurocirugía 18: 333-336

3. Bavbek.M Altmors.MN Caner.HH Bilezikci.B and Agildere.M. et al, (2001) Lumbar myxopapillary ependymoma mimi.MNcking neurofibroma Spinal cord issue: 8, volume: 39, year:,pages: $449-$ 452

4. Byung Soo Kim, SangWooKim, Kyung-WooKwak, and Jun Huck Choi, (2013) Extra and Intramedullary Anaplastic Ependymoma in Thoracic Spinal Cord Korean J Spine. 10(3): 177-180.

5. Celli P, Cervoni L,Cantore G. (1993) Ependymoma of the filum terminale: treatment and prognostic factors in a series of 28 cases.Acta Neurochir (Wien). 124(2-4):99-103.

6. Daniel R. Fassett, Meic H. Schmidt, (2003) Lumbosacral Ependymomas: A Review of the Management of Intradural and Extradural Tumors Neurosurg Focus. 15(5)

7. P De Bonis, N Montano, B Cioni, C Colosimo, and L.Lauriola, et al, (2009) Primary extramedullary extradural ependymoma of the thoracic spine mimicking a schwannoma Journal of Neurology, Neurosurgery \& Psychiatry 80:579-581

8. Duffau H, Gazzaz. Mkuias M, Fohanno D. Primary intradural extramedullary ependymoma: case report and review of the literature.Spine (Phila Pa 1976) 2000 Aug 1;25(15):1993-1995. 